\title{
Gaze-evoked eyelid and ocular nystagmus inhibited by the near reflex: unusual ocular motor phenomena in a lateral medullary syndrome
}

\author{
ROBERT B. DAROFF, 1 WILLIAM F. HOYT, ${ }^{2}$ MICHAEL D. SANDERS, ${ }^{3}$ \\ AND LOUIS R. NELSON
}

From the Neuro-ophthalmology Service of the Departments of Neurology, Neurosurgery, and Ophthalmology, University of California School of Medicine, San Francisco, U.S.A.

Rhythmic movements of the upper eyelids are infrequent manifestations of brain-stem disease. Gowers (1879) noted the close coordination between movements of the upper lids and eyeballs in vertical nystagmus. He attributed this coordinated movement to the natural synkinesis of the levator palpebrae superioris and superior rectus muscles; this clinical observation was later verified electrophysiologically (Bjørk and Kugelberg, 1953). Raudnitz (1897), in a paper on spasmus nutans, was perhaps the first to describe lid movements in association with horizontal ocular nystagmus. Pick (1916) employed the term 'lid nystagmus' (Nystagmus des Oberlides) to designate a phasic rhythmic jerking of the upper lid consisting of a fast upward flick and a slower downward drift. In his patient the lid nystagmus was evoked principally by convergence. Later that same year Popper (1916) reported a form of lid nystagmus in which a clinically obvious upward jerking of the lids occurred synchronously with the fast phase of a gaze-evoked horizontal ocular nystagmus.

Subsequent reports of lid nystagmus have been rare. Sittig (1917), and Wilbrand and Saenger (1921) presented single cases of gaze-evoked lid and ocular nystagmus. Brain-stem dysfunction was evident in these cases, but discrete localization of the lesion could not be made pathologically or clinically.

We have described in the accompanying report (Sanders, Hoyt, and Daroff, 1968) the electromyographic analysis in a case of convergence-evoked (Pick-type) lid nystagmus. The present report will: (1) describe clinical and electrodiagnostic findings from a typical example of the Popper-type of gazeevoked oculopalpebral nystagmus in a young woman with an otherwise paradigmatic lateral medullary

${ }^{1}$ USPHS Special Fellow in Neuro-ophthalmology, No. NB1820-01. 'Reprint requests should be addressed to Dr. Hoyt.

${ }^{2}$ Fellow in Neuro-ophthalmology sponsored by the British Medical Research Council. syndrome, and (2) discuss a unique feature of the nystagmus: its total arrest or inhibition by the near reflex.

\section{CASE REPORT}

In June 1967, a 30-year-old housewife suddenly became vertiginous as she turned her head to the left whileo stooping. The spinning sensation stopped when she straightened up. Two weeks later, when she awoke in the morning her right arm, leg, and the right side of hes body were numb. This sensation persisted for four days and then spread to involve the left side of her face an tongue. During the day she developed more signs and symptoms: vertigo precipitated by movement of heo head, a tendency to veer to the left when walking, mils left-sided ptosis, difficulty in swallowing, and hoarseness of her voice. Two days later she had several short episodes of vertical diplopia but her symptoms of vertigo and dysphagia had stopped.

Several members of the patient's family had systemic hypertension and she had had pre-eclamptic symptoms and hypertension while pregnant in 1964. The year before her neurological illness she had taken oral contraceptives on an irregular schedule, and had stopped the medication four weeks before the episode of vertigo.

Physical examination at another institution in July 1967, disclosed the following: (1) brachial blood pressure of $160 / 110 \mathrm{~mm} / \mathrm{Hg},(2)$ an unsteady gait with a tendency to fall to the left, (3) normal strength in all extremities, (4) normal symmetrical reflexes, (5) absence of cerebellar signs in the upper and lower extremities, (6) hypaesthesia of the left face and the right side of the body (arm, trunk, and leg), (7) weakness and numbness of the left side of the oropharynx, (8) narrowing of the left palpebral fissure with ipsilateral miosis and anhidrosis, (9) a diminished left corneal reflex, (10) decreased tearing in the left eye, and (11) 'severe' horizontal nystagmus in both directions.

The patient's crossed sensory loss, oculosympathetic paresis, palatal weakness, dysphonia, unsteady gait, and nystagmus indicated a focal lesion in the left lateral portion of the medulla (Wallenberg's syndrome). The 
systemic hypertension and possibly the oral contraceptives were regarded as aetiological factors. Extensive laboratory, electrophysiological, and radiological examination (two lumbar taps, a glucose tolerance test, radiographs of her skull, bilateral carotid arteriograms, myelography, intravenous pyelograms, renal arteriograms, electrocardiograms, and electroencephalography) produced normal data that did not clarify further the nature of the focal vascular lesion or the cause of the systemic hypertension.

The patient was placed on anti-hypertensive medication and discharged from the hospital. During the next two months her gait improved considerably and the sensory loss gradually diminished.

CLINICAL OCULAR MOTOR FINDINGS When examined at the University of California Medical Center $2 \frac{1}{2}$ months after the onset of her illness the patient's range of ocular movement, including convergence, was normal. There was no nystagmus during horizontal versions with the patient following the examiner's finger, but marked gaze-evoked horizontal nystagmus appeared when she looked to either side on command or focused in the distance on a laterally placed object. The lid and ocular nystagmus began as the patient's eyes were deviated about $20^{\circ}$ laterally. The amplitude of both increased steadily to a maximum as ocular deviation approached $45-50^{\circ}$. The fast phase of this nystagmus seemed to correspond with the direction of gaze. Nystagmus did not occur during upward or downward gaze. The amplitude of the nystagmus was greater in left lateral gaze. In synchrony with these abnormal ocular movements both upper eyelids jerked upward from their resting position. This gaze-evoked lid nystagmus was sustained and was most apparent when the patient looked to her right or left with her eyes slightly $\left(10-15^{\circ}\right)$ below the horizontal. The amplitude of the lid movement varied; usually three or four equal jerks of the lids were followed by several jerks of lesser amplitude, a few 'missed beats', and then a series of full-amplitude jerks. The frequency of the lid and ocular nystagmus appeared equal. Although the patient occasionally blinked during sustained lateral gaze, the orbicularis oculi muscles did not seem to participate in the phasic levatoroculomotor activity; the upper lids jerked upward and then floated back to their resting position above the pupillary margin (levator contraction and relaxation); the lower lids did not move.

Abrupt suppression of the jerking movements of lids and eyes occurred as the patient shifted her attention from the distance to a nearby object (Fig. 1). This suspension of the nystagmus during lateral gaze was accompanied by narrowing of the pupils. The nystagmus immediately resumed when fixation was redirected to the distance.

ELECTRONYSTAGMOGRAPHiC STUdies Details of the lid and eye nystagmus were analysed from electro-oculographic recordings obtained with two pairs of nonpolarizable $\mathrm{Ag} / \mathrm{AgCl}$ electrodes, and an Offner Model $\mathrm{R}$ dynograph (AC coupled with a time constant of $1 \mathrm{sec}$ ). Muscle and $60 \mathrm{c} / \mathrm{s}$ artefacts were eliminated by a high frequency filter.

One pair of electrodes was placed horizontally near the medial and lateral canthi of the left eye; the horizontal nystagmus was recorded from these electrodes. The second pair of electrodes, placed below the brow and over the inferior orbital rim, recorded changes in the surface potential (in the absence of blinking or vertical nystagmus) that indicated upward or downward deflections of the upper lid.

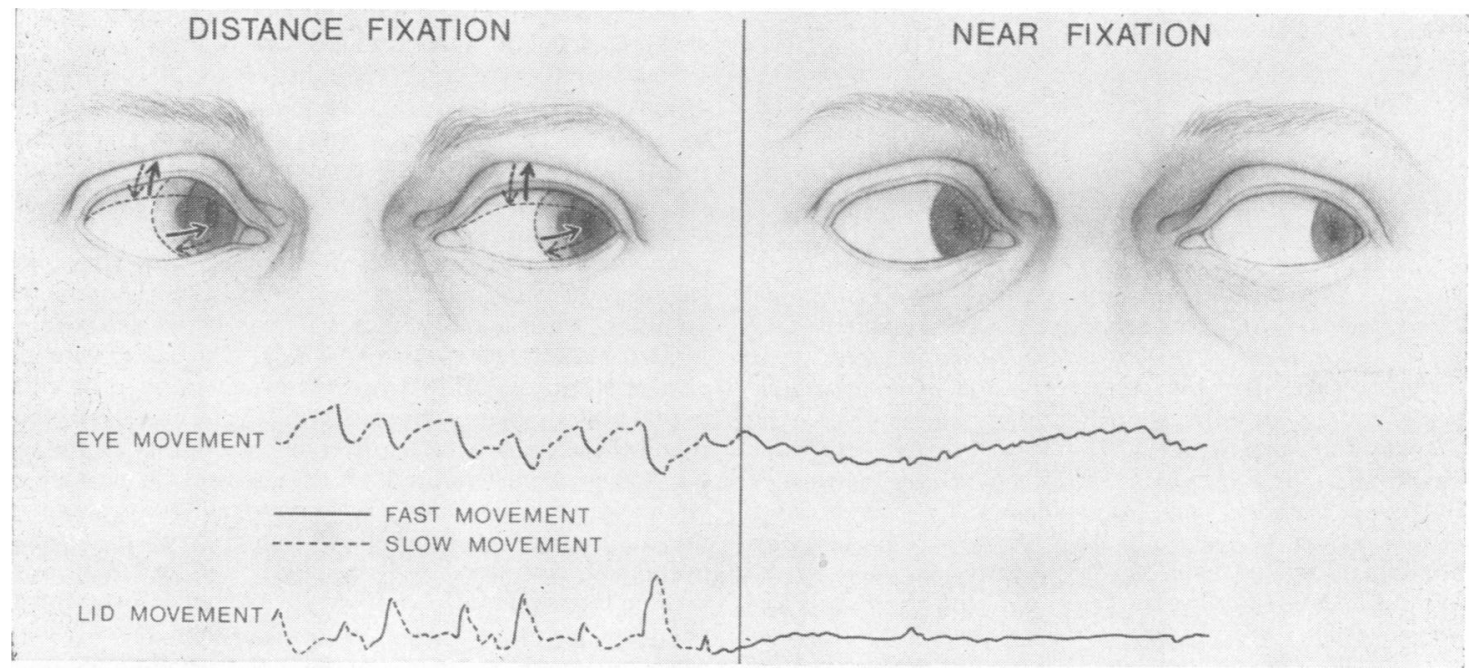

FIG. 1. Gaze-evoked ocular and lid nystagmus occur during gaze at a distant object. The fast phases of both the eye and eyelid movements (indicated by solid arrows in diagram above and solid lines in nystagmogram below) are synchronous. The abnormal movements stopped during near fixation. 
There was no electrical evidence of ocular or lid movement when the patient looked straight ahead (in room illumination, in darkness, and with closed eyes). In confirmation of the clinical observations, nystagmographic recordings displayed rhythmical movements of the eyes and upper lids whenever the patient looked to the side.

1. NYSTAGMUS EVOKED IN LEFT LATERAL GAZE (EYeS TURNED TOWARD THE SIDE OF THE BRAIN-STEM LESION; PATIENT LOOKING IN THE DISTANCE) Ocular nystagmus Nystagmograms showed the following: (1) sustained horizontal nystagmus, predominantly pendular interspersed with short runs of modified jerk-type oscillations with the fast component to the left (in the direction of gaze) (Fig. 2A, B); (2) the amplitude of the ocular movement was regular in height and low to moderate in degree, (3) the frequency of pendular oscillations averaged $3 \cdot 5 / \mathrm{sec}$ ( range $=2-7 / \mathrm{sec}$ ), the jerk-type $3 / \mathrm{sec}$.

Upper lid nystagmus A variability of form, amplitude, and rate was displayed: (1) the upward phase was more rapid, the passive downward phase slower; (2) the

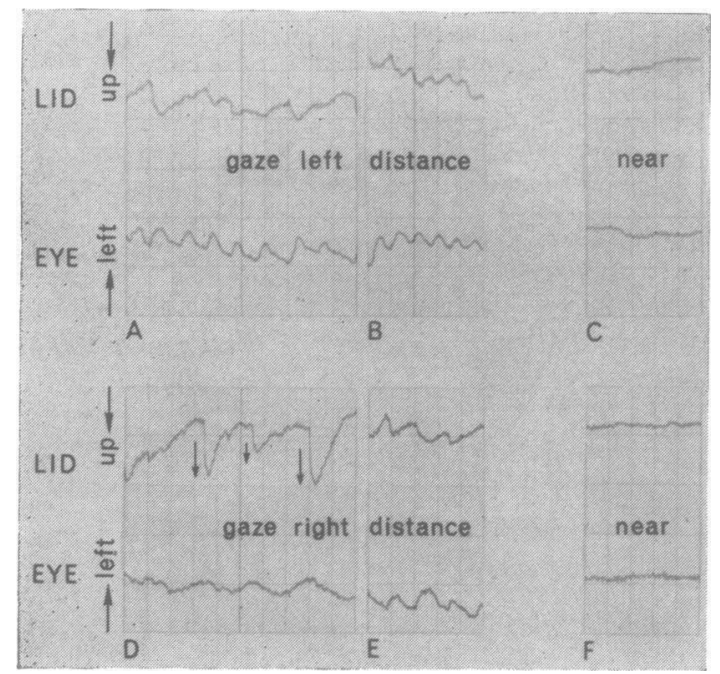

FIG. 2. Electronystagmograms of gaze-evoked ocular and lid nystagmus with eyes open in illuminated room (see text for details). With gaze to the left during fixation on a distant object, note the admixture of pendular and jerk ocular nystagmus in $A$, and the purely pendular forms in $B$.

- The onset of the up-jerks of the lids in $A$ and $B$ are always synchronous with the onset of the left beating movement of the eyes. During gaze to the right with fixation on a distant object ( $D$ and $E$ ), note the lack of synchrony between the up-jerking of the lids (arrows) and the low voltage pendular oscillations of the eyes in D. In E, the upward lid movements are synchronous with the left beating eye movements. The suppression of both the ocular and lid nystagmus by the near reflex is indicated in C (left gaze) and $F$ (right gaze). (Scale: 1 sec equals distance between heavy vertical grid lines.) average frequency was $2.5 / \mathrm{sec}$; occasionally a short $\frac{0}{2}$ $(1-2 / \mathrm{sec})$ run of low amplitude lid oscillations had a rate $\underset{\mathbb{Q}}{Z}$ approaching $7 / \mathrm{sec}$.

Synchrony of eye and lid Nystagmograms established 0 that each upward jerk of the lid (levator contraction) was $\subseteq$ synchronous with a jerk (or pendular) movement of the eyes to the left (Fig. 2A, B). Every third or fourth beat of ${ }_{\omega}^{T}$ ocular nystagmus occurred without a corresponding lid movement. The optimum rate of a regular and sustained $\frac{\bar{v}}{\mathrm{v}}$ lid nystagmus appeared to be $2-2.5$ jerks/ $/ \mathrm{sec}$; the corresponding rate of the ocular nystagmus was $3-3 \cdot 5 / \mathrm{sec}$.

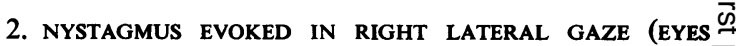
TURNED AWAY FROM THE SIDE OF THE BRAIN-STEM LESION; FIXATION IN THE DISTANCE). Nystagmograms recorded $\overline{\bar{\sigma}}$ with eyes turned conjugately to the right revealed distinct $\frac{\bar{\Phi}}{\vec{D}}$ differences from the nystagmus in left gaze.

Ocular nystagmus It was irregular and usually pendular, but was jerky in $15 \%$ of the beats. The average frequency was $4 / \mathrm{sec}$ with the fast phase to the left $\overrightarrow{0}$ (Fig. 2D, E) (opposite to the direction of gaze).

Lid nystagmus This consisted of irregular upward $\vec{\omega}$ jerks of variable amplitude and velocity, and an average frequency of $2 \cdot 5 / \mathrm{sec}$. Most up-jerks of the lid were $\overline{3}$ synchronous with jerking or pendular eye movements? toward the left (Fig. 2E). In several recordings, upward $\omega$ jerks of the lids were asynchronous with slow, low amplitude (horizontal) oscillations of the eyes (Fig. 2DE

3. FACTORS MODIFYING NYSTAGMUS IN CONJUGATE LATERA GAZE In darkness With the patient instructed to visuas ize an imaginary distant object, the ocular nystagm evoked by lateral gaze in either direction was $3 / s e c$ and consisted of regular runs of pendular or jerk form (ratio 1:1). The amplitude of the lid nystagmus was. increased; up-jerks were synchronous with eye move $\overrightarrow{\bar{Q}}$ ments to the left.

Lid closure with the patient instructed as above, caused slowing of lateral gaze nystagmus to 1-2 beats/sec.

4. EFFECT OF THE NEAR REFLEX ON EVOKED EYE AND LID NYSTAGMUS When the patient changed her attention from the distance to a laterally placed nearby object, the nystagmograms showed an abrupt and usually complete cessation of nystagmus (Fig. 2C, F). This phenomenon was not dependent on fixation alone, for suppression also occurred as the patient changed her attention from the distance to near while she was in total darkness, or with closed lids. The lid nystagmus always stopped during any shift of attention to a close point, but complete suppression of the ocular nystagmus required asymmetrical convergence of the abducting eye. When the eyes were kept deviated to the extreme of lateral gaze, necessitating asymmetrical convergence of the adducting eye, incomplete damping of the ocular nystagmus resulted. Occasionally, the partially suppressed nystagmus completely changed its form; pendular eye movements during gaze at the distance were converted to an unsustained jerk nystagmus.

During eyelid closure with distant lateral visual $\mathcal{N}$ imagery, an irregular oscillation was recorded from the $N$ vertical electrodes. Clinically it appeared that an

$$
\sum_{\mathbb{D}}^{C}
$$




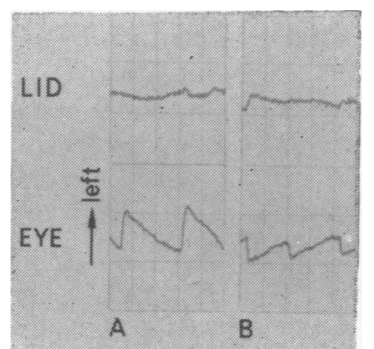

FIG. 3. Electronystagmogram during horizontal optokinetic nystagmus in both directions $(A$ and B) demonstrates lack of associated rhythmic lid movements.

orbicularis flutter or lid tremor was occurring. At near gaze all electronystagmographic evidence of abnormality in the lid tracing abruptly stopped.

5. OPTOKINETIC NYSTAGMUS Electronystagmograms of ocular movements evoked by optokinetic stimuli showed no evidence of associated rhythmic upper lid movements (Fig. 3A, B). Rare irregular upward jerks of the lid were recorded; these occurred in synchrony with the fast phase of the visually evoked nystagmus. Spontaneous blinks occurring during optokinetic or gaze-evoked nystagmus were always synchronous with the onset of the fast phase of the ocular nystagmus, confirming Jung's (1953) observation.

ELECTROMYOGRAPHY Electrical activity in the pretarsal fibres of the lower lid was picked up through a small concentric needle electrode and amplified by electronic equipment that is standard for ocular electromyography (Loeffler, Slatt, and Hoyt, 1966). Recordings were made during upper lid and ocular nystagmus evoked in lateral gaze. There was no EMG evidence of phasic activity in the fibres of the orbicularis oculi.

QUANTITATIVE CALORIC STIMULATION Differential caloric testing was performed by the technique of Fitzgerald and Hallpike (1942); observation of eye movements was improved by Frenzel spectacles. Warm and cold water stimulation in each ear evoked nystagmus of equal duration. There was no indication of canal paresis or directional preponderance. Lid movements were absent during ocular nystagmus in the primary position of gaze. However, when the patient turned her eyes conjugately in the direction of the fast phase, she had an exaggerated (apparently facilitated) form of lid nystagmus. For a brief period during left-beating caloric nystagmus and voluntary left lateral gaze, there was synchronous activity in the left brow and forehead; each upward jerk of the lid and left jerk of the eyes was accompanied by elevation of the left brow and wrinkling of the left forehead. This peculiar frontalis nystagmus has been described by Carmichael and Critchley (1925).

\section{DISCUSSION}

Nystagmus in the lateral medullary syndrome is commonly attributed to lesions of the caudal vestibular nuclei (Currier; Giles, and De Jong, 1961) or the cerebellar pathways (Isch, 1957). Fisher,
Karnes, and Kubik (1961) have demonstrated, however, that nystagmus may occur in the absence of pathological involvement of these structures. A similarly enigmatic nystagmus is occasionally encountered in spinal cord lesions (Sercl and Kovarik, 1960). In both conditions, interruption of the spinovestibular tracts is a potential cause of the nystagmus. Joint receptors from the whole body, and the upper cervical region in particular, supply tonic postural impulses to the vestibular nuclei (McCouch, Deering, and Ling, 1951). These impulses traverse pathways in the dorsal lateral medulla and terminate in the vestibular nuclei (Mehler, Feferman, and Nauta, 1960; Brodal, Pompeiano, and Walberg, 1962). Disruption of both the neck receptors (Biemond, 1961; Philipszoon, 1967) and the cord pathway (Netzer, 1963) have been implicated as a cause of nystagmus.

The ocular nystagmus usually described in lateral medullary lesions may be horizontal or rotary and is of greatest amplitude with gaze toward the side of the lesion (Currier et al., 1961). Peculiar features of the nystagmus have been reported, such as the case of Moberg, Preber, Silfverskiöld, and Vallbo (1962), in which a continuous horizontal nystagmus reversed direction and was unaffected by caloric stimulation when the eyelids were closed. Our patient displayed other unusual characteristics of horizontal nystagmus in this syndrome: lid and eye nystagmus were present only during gaze laterally in the distance (Fig. 1).

Gaze-evoked lid nystagmus of the Popper-type exemplified in our case consists of rapid phasic twitches of the levator muscles in which the upper lids elevate and slowly return to their resting position. The onset of the lid elevation was almost always synchronous with the start of the left beating phase of the ocular nystagmus: toward the side of the medullary lesion. This synchrony was present during both pendular and jerk forms of the ocular nystagmus. The lid movements did not occur when a left beating ocular nystagmus was precipitated by optokinetic or caloric stimulation in the primary position. The lid nystagmus, therefore, was not driven by the ocular nystagmus as the result of an obligatory synkinesis within the ocular motor neuronal pool. It represents the clinical expression of (abnormal) phasic excitatory activity in the levator nucleus.

As previously noted, lid nystagmus is a rare phenomenon. Why the levator muscles do not participate more frequently in the phasic neural activity of ocular nystagmus is unknown. Strong tonic inhibitory influence from the pretectal region presumably prevents phasic excitation of levator motoneurones under most circumstances. The 
mechanism by which a focal medullary lesion can suspend this inhibition during lateral gaze is obscure. The complexity is compounded upon consideration of the reverse situation described by us (Sanders et al., 1968) in which lid nystagmus is precipitated only by convergence.

Adams's (1957) theory that a micro-blink precedes levator excitation in lid nystagmus is theoretically appealing in view of the normal brain-stem synkinesis linking blinks with ocular refixation (Gordon, 1951; Kennard and Glaser, 1964). However, the absence of phasic orbicularis activity during lid nystagmus in our patient eliminates this possibility.

The stabilization of the disordered motor output -that is, cessation of gaze-evoked lid and eye nystagmus-while looking at a nearby object may provide indirect evidence about the origin of the nystagmus. The phylogenetically advanced occipitomesencephalic control systems override or dampen the nystagmoid activity in the brain-stem gaze mechanism initiated by retinal, vestibular or, particularly, cervical inputs. The inhibitory effects of light, visual fixation, and convergence on evoked vestibular nystagmus are well known (Mahoney, Harlan, and Bickford, 1957; Jung and Kornhuber, 1964; Philipszoon, 1967).

The data cited above concerning the inhibitory effects of convergence were obtained with the eyes in the mid-position. The near reflex has no effect, in our experience, on caloric-induced nystagmus with the eyes deviated laterally in the direction of the fast component. These observations, supported by the normal differential caloric testing, suggest that the dramatically inhibited gaze-evoked nystagmus in our patient was not caused by primary vestibular dysfunction, but instead resulted from a lower level disturbance. In comparison with the labyrinthine input, the ascending spinovestibular input in man is subordinate: its ocular motor effects are relatively insignificant and are easily suppressed by visual reflexes. The lid and ocular gaze nystagmus displayed by our patient was readily suppressed by the near reflex in the light, in the dark, or even behind closed lids; we believe the nystagmus may be explained as an effect of diminished and asymmetric spinovestibular tonus.

The pathophysiological abnormality in our patient, whatever its nature, resulted in a disturbance in the complex servomechanism (control system subserving ocular motor stability) that is similar to that encountered in congenital nystagmus. The gaze-evoked nystagmus was more often pendular than jerky in type. This feature is unusual in acquired forms of nystagmus but frequent in the congenital variety. Similarly fixation at a near object characteristically dampens congenital nystagmus (Forssman,
1964). The causes of congenital nystagmus are으 unknown but undoubtedly are manifold. It is $\underset{\odot}{Z}$ possible that a disturbance of spinovestibular input $\stackrel{ }{\triangle}$ may be the underlying mechanism in some cases.

In conclusion it should be stressed that there was no evidence of any abnormality in our patient when 0 her extraocular movements were tested by the usuale technique of following a nearby object. Only when $\stackrel{5}{=}$. her fixation was directed at a distance did the oculo-palpebral nystagmus become manifest. The. clinical examination for gaze-evoked nystagmus $\vec{\Rightarrow}$ should therefore include observation of the eyes $\stackrel{?}{?}$ while the patient looks in the distance.

\section{SUMMARY}

A young woman with a lateral medullary syndrome had gaze-evoked lid and ocular nystagmus. The $\vec{\circ}$ nystagmus was present only with distant lateral fixation and was promptly inhibited by the near $\vec{\omega}$ reflex. It is believed that the nystagmus represents? spino-vestibular pathway disruption, the effects of $\stackrel{5}{5}$ which are readily dampened by the higher level ${ }_{\omega}^{0}$ corticomesencephalic activity of the near reflex.

Similarities with congenital nystagmus are ment tioned, and it is emphasized that clinical examinatiog for gaze-evoked nystagmus should include observa-o tion of the eyes both while the patient looks in the distance and at a near object.

The authors gratefully acknowledge the cooperation @ำ Doctor J. B. Drori in permitting us to study his patieng.

\section{REFERENCES}

Adams, A. (1957). Nystagmographische Untersuchungen über deno Lidnystagmus und die physiologische Koordination von Lidschlag und rascher Nystagmusphase. Arch. Ohr.-, Nas.-, $\frac{\supset}{\bar{O}}$ u. Kehlk.-Heilk., 170, 543-558.

Biemond, A. (1961). Nystagmus de position d'origine cervicale. ำ Psychiat. Neurol. Neurochir. (Amst.), 64, 149-157.

Bjørk, A., and Kugelberg, E. (1953). The electrical activity of the muscles of the eye and eyelids in various positions and during movement. Electroenceph. Clin. Neurophysiol., 5, 595-602.

Brodal, A., Pompeiano, O., and Waloerg, F. (1962). The Vestibular Nuclei and Their Connections, Anatomy and Functional? Correlations. Oliver and Boyd, Edinburgh.

Carmichael, E. A., and Critchley, M. (1925). The relations between:eye movements and other cranial muscles. Brit. J. Ophthal., 9, 49-52.

Currier, R. D., Giles, C. L., and De Jong, R. N. (1961). Some com-무 ments on Wallenberg's lateral medullary syndrome. Neurology음 (Mineapp.), 11, 778-791.

Fisher, C. M., Karnes, W. E., and Kubik, C. S. (1961). Lateral'medullary infarction. The pattern of vascular occlusion. 음 J. Neuropath. exp. Neurol., 20, 323-379.

Fitzgerald, G., and Hallpike, C. S. (1942). Studies in human vestibular function; observations on the directional preponderance ('Nystagmusbereitschaft') of caloric nystagmus resulting from cerebral lesions. Brain, 65, 115-137.

Forssman, B. (1964). A study of congenital nystagmus. Acta oto- 을. laryng. (Stockh.), 57, 427-449.

Gordon, G. (1951). Observation upon the movements of the eyelids. م Brit. J. Ophthal., 35, 339-351.

Gowers, W. R. (1879). The movements of the eyelids. Med.-chir. N Trans., 62, 429-440. 
Isch, F. (1957). Formes de Début et Séquelles du Syndrome Rétroolivaire de Déjerine. Rev. neurol., 97, 350-365.

Jung, R. (1953). Neurophysiologische Untersüchungsmethoden, in Handbuch der Inneren Medizin, 4th Ed. (Neurologie, Vol. V, Pt. 1), pp. 1353-1354. Ed. C. Bergmann, W. Frey, and H. Schwiegk. Springer-Verlag, Berlin.

- - , and Kornhuber, H. H. (1964). Results of electronystagmography in man: the value of optokinetic, vestibular, and spontaneous nystagmus for neurologic diagnosis and research, in The Oculomotor System, pp. 428-482. Ed. M. B. Bender. Harper and Row, New York.

Kennard, D. W., and Glaser, G. H. (1964). An analysis of eyelid movements. J. nerv. ment. Dis., 139, 31-48.

Loeffler, J. D., Slatt, B., and Hoyt, W. F. (1966). Motor abnormalities of the eyelids in Parkinson's disease. Electromyographic observations. Arch Ophthal., 76, 178-185.

Mahoney, J. L., Harlan, W. L., and Bickford, R. G. (1957). Visual and other factors influencing caloric nystagmus in normal subjects. Arch. Otolaryng., 66, 46-53.

McCouch, G. P., Deering, I. D., and Ling, T. H. (1951). Location of receptors for tonic neck reflexes. J. Neurophysiol., 14, 191-195.

Mehler, W. R., Feferman, M. E., and Nauta, W. J. H. (1960). Ascending axon degeneration following anterolateral cordotomy: an experimental study in the monkey. Brain, 83, 718-750.

Moberg, A., Preber, L., Silfverskiöld, B. P., and Vallbo, S. (1962) Imbalance, nystagmus and diplopia in Wallenberg's syndrome.
Clinical analysis of a case and post-mortem examination. Acta oto-laryng. (Stockh.), 55, 269-282.

Netzer, H. R. (1963). Ocular nystagmus following cervical cord stimulation. Uni. Mich. med. Bull., 29, 309-313.

Philipszoon, A. J. (1967). Some aspects of electronystagmography. J. Laryng., 81, 887-910.

Pick, A. (1916). Kleine Beiträge zur Neurologie des Auges; 11. Úber den Nystagmus der Bulbi begleitende gleichartige Bewegungen des oberen Augenlides (Nystagmus des Oberlides.), Arch. Augenheilk., 80, 36-40.

Popper, E. (1916). Ein Beitrag zur Frage des "Lidnystagmus". Mschr. Psychiat. Neurol., 39, 188-192.

Raudnitz, R. W. (1897). Zur Lehre von Spasmus Nutans. Jb. Kinderheilk., 45, 145-176.

Sanders, M. D., Hoyt, W. F., and Daroff, R. B. (1968). Lid nystagmus evoked by ocular convergence: an ocular electromyographic study. J. Neurol. Neurosurg. Psychiat., 31, 368-371.

Sercl, M., and Kovarik, J. (1960). A contribution to the question of distant signs in tumors of the spinal cord with special regard to nystagmus. $\mathrm{Zbl}$. Neurochir., 20, 347-359.

Sittig, O. (1917). Kasuistischer Beitrag zur Frage des Lidnystagmus nebst Bemerkungen zu einer eventuellen lokalisatorischen Bedeutung. Neurol. Centralbl., 36, 72-74.

Wilbrand, H., and Saenger, A. (1921). Die Neurologie Des Auges. Vol. 8. Die Bewegungsstörungen der Augenmuskein, p. 404. Bergmann, Munich and Wiesbaden. 